\title{
Editorial
}

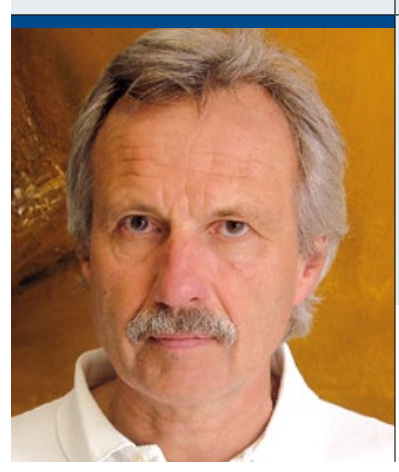

"Mit zunehmendem Einfluss der Ökonomie und der Jurispru-

denz bleibt die Humanität in der Medizin auf der Strecke."

\section{Von Menschen und Mäusen}

$\mathrm{D}$ a haben die Rotkäppchen vom Bundesgerichtshof (BGH) mal wieder zugeschlagen: „Das Absehen von einer ärztlichen Maßnahme ist nicht erst dann behandlungsfehlerhaft, wenn die Maßnahme 'zwingend' geboten war, sondern bereits dann, wenn ihr Unterbleiben dem im Zeitpunkt der Behandlung bestehenden medizinischen Standard zuwider lief." (AZ: VI ZR 67/15; Anmerkung der Chefredaktion: sehr lesenswert). Den medizinischen Standard erklärt das BGH dem Wicht in Weiß in unnachahmlicher Präzision als das „Verhalten, welches von einem gewissenhaften und aufmerksamen Arzt in der konkreten Behandlungssituation aus der berufsfachlichen Sicht seines Fachbereichs vorausgesetzt und erwartet werden kann".

Dieses Urteil wird angesichts der Multimorbidität der vergreisenden Gesellschaft die Therapieentscheidung dem unter Zeitdruck stehenden Arzt vor Ort nicht erleichtern. Es dürfte ihn zur Vermeidung haftpflichtträchtiger Unterlassungen vielmehr dazu motivieren, den gesamten Kanon evidenzbasierter Maßnahmen an seinem Patienten abzuarbeiten, ihn also unter anderem auch umgehend zum nächsten Spezialisten zu "turfen“. Dann beginnt der muntere „Spezialisten-Ringelreihen“. Die Negierung des Schicksalhaften, verbunden mit der reflexartig gestellten Schuldfrage und Anrufung der Gerichte unter pharisäerhafter Verleugnung monetärer Erfolgsaussichten bringt für die medizinische Versorgung keine Vorteile. Pikant ist es, wenn Urteile für einen Verblichenen erstritten werden.

\section{Money makes the world go round}

Ende 2015 überschritten die weltweiten Umsätze der Pharmazeutischen Industrie eine Billion Dollar. 46 neue Wirkstoffe wurden 2015 rund um den Globus neu eingeführt. Ein Drittel ist für die Behandlung seltener Erkrankungen bestimmt. An Medikamenten gegen seltene Erkrankungen, und ganz besonders an Krebsmitteln, verdient die Pharmaindustrie erkleckliche Sümmchen. Beispielsweise kosten 30 Tabletten eines gegen Leukämie eingesetzten
Krebspräparats eines Herstellers hierzulande 3.400 Euro, in einem anderen EU-Land sind sie hingegen für 1.000 Euro weniger zu haben. Fragt sich, wie hoch der Gewinn bei solchen Präparaten ist.

Sieben von elf neuartigen Onkologika erhielten zudem den Orphan-Drug-Status. Die gesundheitspolitische Forderung, das Nutzen-Risiko-Potenzial der Orphan Drugs im Zweifel überprüfen zu lassen, lehnte der Pharmaverband BPI ab.

Eine lukrative Geschäftsidee hat auch eine andere Pharmafirma für sich entdeckt: Sie kauft zunehmend ältere Monopolpräparate auf, zum Beispiel ein Präparat zur Prophylaxe und Therapie tiefer Beinvenenthrombosen für die Fälle, in denen Heparin nicht angewendet werden soll oder darf. Der Preis wurde zum Jahresende 2015 kurzerhand von 26 Euro pro Ampulle auf satte 97 Euro erhöht.

In den USA hat ein Hedgefonds ein 60 Jahre altes Mittel gegen Infektionen aufgekauft. Nachdem dieses Medikament in der HIV-Therapie eingesetzt werden darf, stieg der Preis pro Tablette von 13,50 Dollar auf 750 Dollar pro Tablette. Feine Rendite für die Investoren.

$\mathrm{Zu}$ denken gibt auch die zunehmende Zahl von Werbespots, die um Nachrichtensendungen herum drapiert werden und der potenziellen Kundschaft eine sagenhafte Wirkung des beworbenen Produkts vorgaukeln: Kaum auf die Haut geschmiert, kann der Anwender Bocksprünge vollführen, nachdem er zuvor noch dem Rollator zur Last gefallen ist.

Angesichts all dieser Entwicklungen drängt sich die bittere Erkenntnis auf, dass mit zunehmendem Einfluss der Ökonomie und der Jurisprudenz die Humanität in der Medizin an Boden verliert.

Ihr

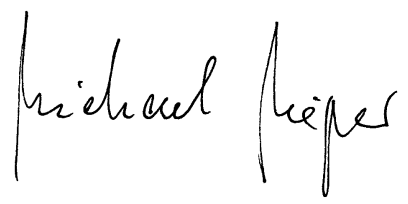

